\title{
Patterns of chronic benzodiazepine use in the elderly
}

\author{
Vanessa Sgnaolin ${ }^{1}$, Paula Engroff ${ }^{2}$, Camila Pereira Andrade ${ }^{3}$, Fernanda Loureiro ${ }^{1}$, Eduardo Lopes Nogueira ${ }^{1,4}$, \\ Alfredo Cataldo Neto1,4, Irenio Gomesi,5
}

- Post-Graduate Program in Biomedical Gerontology of Pontifícia Universidade Católica do Rio Grande do Sul (PUCRS), Porto Alegre, RS, Brazil.

2 Institute of Geriatrics and Gerontology of PUCRS, Porto Alegre, RS, Brazil.

${ }^{3}$ Pharmacy College of PUCRS, Porto Alegre, RS, Brazil.

${ }^{4}$ Department of Psychiatry Hospital São Lucas of PUCRS, Porto Alegre, RS, Brazil.

${ }_{5}^{5}$ Department of Neurology Hospital São Lucas of PUCRS, Porto Alegre, RS, Brazil.

Submitted: 30/6/2016 - Accepted: 12/9/2016

DOl: 10.1590/0101-60830000000089

\begin{abstract}
Background: In several countries, prevalence studies demonstrate that chronic use of BZD in the elderly population is very high. This scenario has reached pandemic proportions for decades and is an important public health problem. Objectives: To examine the independent association between chronic benzodiazepine use in depression, anxiety and bipolar disorder, as well as other clinical and sociodemographic factors. Methods: This cross-sectional study was developed from a population-based survey and conducted from March, 2011 to December, 2012 using a random sample of 550 elderly people who were enrolled in the Family Health Strategy in Porto Alegre, Brazil. Data was collected from identifying epidemiological and health data (sociodemographic, self-perception health, self-reported diseases, smoking, alcohol and pharmacotherapeutic evaluation) and from the diagnoses of mood and anxiety disorders. Results: Elderly patients diagnosed with depression, anxiety, concomitant depression/anxiety and bipolar disorders, and those who were using antidepressants have a higher risk of benzodiazepine use. Individuals who self-reported drinking alcohol had a lower risk of benzodiazepine use. Discussion: Benzodiazepines are often used by the elderly for long periods, which has a direct impact on the treatment of mood and anxiety disorders and on vulnerable groups such as the elderly, who may be unnecessarily taking these drugs.
\end{abstract}

Sgnaolin V et al. / Arch Clin Psychiatry. 2016;43(4):79-82

Keywords: Elderly, anxiety, benzodiazepines, depression, public health.

\section{Introduction}

Benzodiazepines (BZD) comprise a subgroup of psychotropic drugs that act selectively to allosterically modulate gamma-aminobutyric acid subtype $A\left(\mathrm{GABA}_{\mathrm{A}}\right)$ receptor and mediate inhibitory synaptic transmission throughout the central nervous system ${ }^{1}$. They are commonly recommended for a variety of conditions such as anxiety, depression, somatic complaints, insomnia, alcohol withdrawal, delirium and violence and aggressive behavior in psychoses and disorders induced by neuroleptics ${ }^{2,3}$. The therapeutic indication for this group of drugs should be short term and for specific conditions such as those mentioned above.

Elderly people are more likely to use $\mathrm{BZD}^{4}$, but they feel less secure and have questionable clinical indications for taking BZD such as nonspecific emotional suffering 5 or a chronic insomnia complaint. In several countries, prevalence studies demonstrate that chronic use of BZD in the elderly population is high, ranging from $3.9 \%$ to $35.9 \%{ }^{6-8}$. This scenario has reached pandemic proportions for decades and is an important public health problem, because chronic use of this drug results in an increase in morbidity factors related to the risk of falls, intoxication and worsening of depressive symptoms and cognition ${ }^{9,10}$.

Depressive ${ }^{11,12}$ and anxiety disorders are frequent in the elderly, constituting an important source of emotional suffering and consequently the increased use of this pharmacological class ${ }^{8,13}$. Newer treatment consensus recommendations for depressive and anxiety disorders do not suggest BZDs as a first-line therapeutic ${ }^{14,15}$. The risk/benefit ratio increases when treating these disorders in the elderly, making the indication for BZD even more unfavorable. This is because of pharmacokinetic and pharmacodynamic changes that occur with aging, which may lead to an increased sensitivity of these individuals to the effects of BZD.

Thus, this study aims to examine the independent association between chronic BZD use in depression, anxiety and bipolar disorders, as well as other clinical and sociodemographic factors in a sample of elderly people who are enrolled in the Family Health Strategy (FHS).

\section{Methods}

\section{Study design}

This cross-sectional study was developed from the population-based survey entitled "The multidimensional study of the elderly in the family health strategy in Porto Alegre, Brazil (EMI-SUS)"16. The EMI-SUS was conducted from March, 2011 to December, 2012 and enrolled a random sample of elderly people who were participating in the FHS in Porto Alegre (RS/Brazil). Inclusion criteria were age $\geq 60$ years and records registered in the FHS.

\section{Data collection}

The data collection procedure included identifying epidemiological and health data (sociodemographic, self-perception health, selfreported diseases, smoking, alcohol and pharmacotherapeutic evaluation) that were collected by community health agents at the homes of the elderly and during specialized psychiatric evaluation, which was carried out by professionals trained at the Hospital São Lucas of Pontifícia Universidade Católica do Rio Grande do Sul.

The mood disorder (major depression/dysthymia, bipolar) and anxiety diagnosis was made by psychiatrists using the DSM-IV criteria, and following the mental health evaluation protocol of the study ${ }^{17}$. The validated Brazilian version of the Mini-International Neuropsychiatric Interview (MINI) was used for evaluating psychiatric diagnoses ${ }^{18}$, and the psychometric properties of the instrument were considered satisfactory to excellent, with a good accuracy for anxiety and mood disorders in primary health care in Brazil19.

For pharmacotherapeutic evaluation, the participants were asked to specify all drugs used. In the interview conducted by the 
community health agent, this information was confirmed from prescriptions, drug packaging and medical records at the FHS. Drugs were coded according to the Anatomical Therapeutic Chemical (ATC) classification system recommended by the World Health Organization ${ }^{20}$. In this study, psychotropic medications included were BZD (N05BA, N03AE01), antidepressants (N06A, N06CA01), antiepileptic (N03A), antipsychotics (N05A) and other psychotropic drugs (N04AA02, N04BA01, N05BB01, N06BA07, N06BC01).

\section{Sample size}

The sample size of the study was calculated using a 0.05 significance level. Considering a target population of 22,000 elderly people enrolled by ESF in Porto Alegre, a minimum sample size of 491 elderly people was chosen, considering a $3.5 \%$ acceptable error for an expected prevalence of $20.0 \%$.

\section{Statistical analysis}

Data were analyzed using Statistical Package for the Social Sciences (IBM SPSS Inc. Chicago, Illinois, version 17). The variables were described by the frequency, mean and standard deviation. Associations between categorical variables were tested using Pearson's chi-square test. In specific cases, the chi-square test for linear tendency (ordinal variables with few categories) was used. To control for confounding variables and independence of variables, multivariate analysis was performed through Poisson regression.

\section{Ethical considerations}

This study was approved by the Ethical Research Committee of the Pontifícia Universidade Católica do Rio Grande do Sul (number 10/04967) and Porto Alegre Municipal Department of Health (registration 499/process 001.021434.10.7). All participants were informed of the objectives and research methods and they signed an informed consent form, according to the Guidelines and Norms Regulating Research of Resolution 196/96 of the National Health Council of the Ministry of Health.

\section{Results}

The 550 individuals included in the study were between 60 and 103 years of age (mean age, $68.6 \pm 7.2$ years), and comprised mostly females $(63.1 \%)$. Most of these elderly people were married $(37.8 \%)$, had incomplete primary education $(69.1 \%)$, a little more than half of the individuals $(55.0 \%)$ received less than one minimum wage (250 US dollars) and little more than half of the families (55.5\%) received less than three minimum wages.

The prevalence of BZD use was $7.3 \%$. This prevalence is compared with sociodemographic variables in Table 1 . Those who had been widowed were found to use more BZD $(10.8 \%)$ while single people used less BZD $(1.1 \% ; P=0.044)$. There were no statistically significant differences in the other sociodemographic variables.

Elders diagnosed with mood disorders represented $38.2 \%$ of the total population studied, with depression responsible for $28.8 \%$ and anxiety $20.2 \%$. Elderly people without a diagnosis of mood disorder used less BZD (2.2\%); however, those with depression (15.5\%; $P<$ $0.001)$ and anxiety (10.5\%) used BZD more often. Those who selfidentified and classified their health as poor/very poor used more BZD (21.2\%; $P=0.003)$. Those who drank alcohol had a lower prevalence of use of BZD than those who did not drink alcohol $(1.3 \%, P=0.001$; Table 2).

The average number of drugs used was $4.0 \pm 2.9$ (range, $0-13$ drugs). Individuals who used 5 or more drugs showed a high prevalence of BZD use $(11.7 \%, P<0.001)$. Antidepressants $(32.5 \%$; $P<0.001)$, antipsychotics $(33.3 \% ; P<0.001)$ and the antiepileptic (25.0\%; $P=0.017)$ were the psychotropic classes that were most frequently used concomitantly with BZD (Table 2).
The final model of multivariate analysis was used to determine which variables were independently associated with the BZD use, and the results are presented in Table 3. Elderly people diagnosed with depression, anxiety, depression and anxiety concomitantly and bipolar disorder, and those who were using antidepressants had a higher risk of using BZD. Individuals who self-reported that they drank alcohol had a lower risk of BZD use.

\section{Discussion}

Large-scale BZD use has been widely accepted worldwide, because these drugs have been considered to be effective as anxiolytics and they are safer than the drugs that were previously available, such as barbiturates. The benefit of a lower toxicity and less potential to develop a chemical dependency contributed to the widespread BZD use over the past decades; this transformed a "benefit" into an important public health problem, especially in the elderly who are typically the main consumers this type of drug.

The prevalence of BZD use (7.3\%) is considered high. Brunoni et al. presented data from six universities located in different Brazilian regions (São Paulo, Rio de Janeiro, Salvador, Porto Alegre, Belo Horizonte and Vitória), where they detected a BZD use prevalence of $3.9 \%$ (in those 35 to 75 years of age), and older people were the most likely to use BZD (OR 3.48)8. The prevalence was even higher $(21.7 \%)$ in an elderly community sample of residents of the city of Bambuí, Minas Gerais, Brazil ${ }^{21}$. Prevalence rates in other countries ranged from $16 \%$ in Australia 22 to $31 \%$ in Finland 7 and $36 \%$ in Canada $^{6}$. These results are particularly important because there are guidelines that classify the BZD use as inappropriate, particularly because of side effects in the elderly ${ }^{23}$.

Table 1. Benzodiazepine (BZD) use compared with sociodemographic variables

\begin{tabular}{|c|c|c|c|}
\hline \multirow{2}{*}{$\begin{array}{l}\text { Sociodemographic } \\
\text { variables }\end{array}$} & \multicolumn{2}{|c|}{ BZD use } & \multirow[t]{2}{*}{$P$} \\
\hline & $\begin{array}{l}\text { No } \\
\mathrm{n}(\%)\end{array}$ & $\begin{array}{l}\text { Yes } \\
\mathrm{n}(\%)\end{array}$ & \\
\hline \multicolumn{4}{|l|}{ Gender } \\
\hline Female & $317(91.4)$ & $30(8.6)$ & $0.105^{\dagger}$ \\
\hline Male & 193 (95.1) & $10(4.9)$ & \\
\hline \multicolumn{4}{|l|}{ Age (years) } \\
\hline $60-69$ & 315 (92.6) & $25(7.4)$ & $0.875^{\ddagger}$ \\
\hline $70-79$ & 152 (92.7) & $12(7.3)$ & \\
\hline 80 or more & $43(93.5)$ & $3(6.5)$ & \\
\hline \multicolumn{4}{|l|}{ Race } \\
\hline White & $320(91.2)$ & $31(8.8)$ & $0.270^{\dagger}$ \\
\hline Black & $96(97.0)$ & $3(3.0)$ & \\
\hline Brown & $71(93.4)$ & $5(6.6)$ & \\
\hline Other & $15(93.8)$ & $1(6.3)$ & \\
\hline \multicolumn{4}{|l|}{ Marital status } \\
\hline Married & 190 (92.7) & $15(7.3)$ & $0.044^{\dagger}$ \\
\hline Widowed & $141(89.2)$ & $17(10.8)^{2,1}$ & \\
\hline Divorced & 83 (93.3) & $6(6.7)$ & \\
\hline Single & $90(98.9)$ & $1(1.1)^{-2,5}$ & \\
\hline \multicolumn{4}{|l|}{ Education (years) } \\
\hline 0 & $79(95.2)$ & $4(4.8)$ & $0.299 \neq$ \\
\hline $1-7$ & 341 (91.4) & $32(8.6)$ & \\
\hline 8 or more & 80 (95.2) & $4(4.8)$ & \\
\hline \multicolumn{4}{|c|}{$\begin{array}{l}\text { Individual income (minimum } \\
\text { wage) }\end{array}$} \\
\hline$<1$ & 302 (91.8) & $27(8.2)$ & $0.215^{\ddagger}$ \\
\hline 1 or more & $179(94.7)$ & $10(5.3)$ & \\
\hline Total & $510(92.7)$ & $40(7.3)$ & \\
\hline
\end{tabular}

$\dagger$ Pearson chi-square test; superscript numbers show results of residual analyses. $\ddagger$ Chi-square test for linear tendency. 
Table 2. Benzodiazepines(BZD) use compared with clinical and health variables

\begin{tabular}{|c|c|c|c|}
\hline \multirow[t]{2}{*}{ Clinical and health variables } & \multicolumn{2}{|c|}{ BZD } & \multirow[t]{2}{*}{$P$} \\
\hline & $\begin{array}{c}\text { No } \\
\mathrm{n}(\%)\end{array}$ & $\begin{array}{c}\text { Yes } \\
\mathrm{n}(\%)\end{array}$ & \\
\hline \multicolumn{4}{|l|}{ Mood or Anxiety disorder } \\
\hline No & $307(97.8)$ & $7(2.2)^{-5,3}$ & $<0.001^{\dagger}$ \\
\hline Depression & 87 (84.5) & $16(15.5)^{3,6}$ & \\
\hline Anxiety & $34(89.5)$ & $4(10.5)$ & \\
\hline Depression and Anxiety & $45(86.5)$ & $7(13.5)$ & \\
\hline Bipolarity & $27(84.4)$ & $5(15.6)$ & \\
\hline \multicolumn{4}{|l|}{ Self-perceived health } \\
\hline Great/Good & $183(94.8)$ & $10(5.2)$ & $0.003^{\ddagger}$ \\
\hline Regular & $279(93.6)$ & $19(6.4)$ & \\
\hline Poor/Very poor & $41(78.8)$ & $11(21.2)^{4,0}$ & \\
\hline \multicolumn{4}{|l|}{ Smoker } \\
\hline No & $214(93.4)$ & $15(6.6)$ & $0.161^{\dagger}$ \\
\hline Yes & $183(93.8)$ & $12(6.2)$ & \\
\hline Ex-smoker & $98(88.3)$ & $13(11.7)$ & \\
\hline \multicolumn{4}{|l|}{ Alcohol use } \\
\hline No & $327(90.8)$ & $33(9.2)$ & $0.001^{\dagger}$ \\
\hline Yes & $150(98.7)$ & $2(1.3)$ & \\
\hline \multicolumn{4}{|l|}{ Drug use } \\
\hline 0 & $74(100.0)$ & $0(0.0)^{-2,6}$ & $<0.001^{\ddagger}$ \\
\hline $1-2$ & $111(95.7)$ & $5(4.3)$ & \\
\hline $3-4$ & $127(93.4)$ & $9(6.6)$ & \\
\hline 5 or more & $196(88.3)$ & $26(11.7)^{3,3}$ & \\
\hline \multicolumn{4}{|l|}{ Pharmacological classes } \\
\hline \multicolumn{4}{|l|}{ Antidepressants } \\
\hline No & $458(96.8)$ & $15(3.2)$ & $<0.001^{\dagger}$ \\
\hline Yes & $52(67.5)$ & $25(32.5)$ & \\
\hline \multicolumn{4}{|l|}{ Antipsychotics } \\
\hline No & $498(93.6)$ & $34(6.4)$ & $<0.001+$ \\
\hline Yes & $12(66.7)$ & $6(33.3)$ & \\
\hline \multicolumn{4}{|l|}{ Antiepileptics } \\
\hline No & $501(93.1)$ & $37(6.9)$ & $0.017^{\dagger}$ \\
\hline Yes & $9(75.0)$ & $3(25.0)$ & \\
\hline \multicolumn{4}{|l|}{ Others psychotropics } \\
\hline No & $494(92.9)$ & $38(7.1)$ & $0.524^{\dagger}$ \\
\hline Yes & $16(88.9)$ & $2(11.1)$ & \\
\hline
\end{tabular}

†Pearson chi-square test; superscript numbers show results of residual analyses. ${ }^{\ddagger}$ Chi-square test for linear tendency.

Table 3. Final model of multivariate analysis using Poisson regression

\begin{tabular}{|l|c|c|c|}
\hline Variable & PR & Cl 95\% & $P$ \\
\hline Mood or Anxiety disorder & & & \\
\hline No & 1 & & \\
\hline Depression & 2.92 & $1.08-7.85$ & 0.034 \\
\hline Anxiety & 7.06 & $2.44-20.44$ & $<0.001$ \\
\hline Depression and Anxiety & 3.51 & $1.32-9.37$ & 0.012 \\
\hline Bipolarity & 3.54 & $1.04-12.11$ & 0.044 \\
\hline Antidepressants & & & \\
\hline No & 1 & & \\
\hline Yes & 8.60 & $4.14-17.89$ & $<0.001$ \\
\hline Alcohol use & & & \\
\hline No & 1 & & \\
\hline Yes & 0.23 & $0.06-0.94$ & 0.040 \\
\hline
\end{tabular}

PR: prevalence ratio; $\mathrm{Cl}$ : confidence interval.
The main socio-demographic characteristics related to chronic BZD use were female (8.6\%), white (8.6\%), widowed $(10.8 \%)$ and income less than the one minimum wage (8.2\%). Only the marital status showed a significant difference, with those who had been widowed using more BZDs. In this group, the majority were women who had depression and used antidepressants, which are factors that are strongly related to BZD use ${ }^{24}$. Previous studies that examined the role of living alone or marital status obtained similar results ${ }^{13,25}$. This finding was not an independent factor that was associated with outcome in a multivariate analysis.

The highest frequency of BZD use is associated with a diagnosis of mood or anxiety disorders, poor self-perceived health, the use of five or more drugs and concomitant use of other psychotropic drugs, particularly antidepressants, antipsychotics and antiepileptics. In a multivariate analysis, the factors that remained were diagnosed with depression (RP: 2.92), anxiety (RP: 7.06), depression and anxiety (RP: 3.51) and bipolar disorder (RP: 3.54). When considering these diagnoses, the elderly person with these psychiatric disorders can be considered very likely to receive BZD. These drugs are indicated for use in various syndromes that present as nonspecific emotional suffering. However, in almost all situations, the BZD use is contraindicated in elderly people ${ }^{23}$, as well as in the general population. BZDs are not indicated for moderate to severe depression, and there is also no evidence to support their use in minor depression ${ }^{26}$. Toxic effects, cognitive dysfunction, risk of worsening depression and fall hazards, among others, will probably outweigh any positive effect of the BZD in the elderly.

According to some authors, the concomitant BZD and antidepressant use can be considered a strategy to increase treatment effectiveness ${ }^{27}$. Short-term use is the most widely accepted use of BZD to treat depression and anxiety, mainly to achieve rapid relief of symptoms at the start of therapy. There is subsequent reduction of the antidepressant dose when it starts to show its effect, thus improving the adherence to antidepressant therapy ${ }^{28}$. The rationale for combination treatment is multidimensional, including neurological bases and clinical factors, because of different pharmacokinetic mechanisms and clinical effects. However, this must be balanced because there is the potential for BZD dependency, and there are antidepressants with anxiolytic/sedative effects that can be used instead of BZDs. This association also raises the issue of polypharmacy, which should be an exception in treating elderly people. In multivariate analysis, antidepressants were most often associated with BZD, showing a high chance of co-prescription (RP: 8.60). Data from a Dutch cohort study of people with depression and anxiety found a milder association between BZD and antidepressants (OR: 3.5) ${ }^{13}$, while another Brazilian study showed a strong association (OR: 7.95) ${ }^{8}$.

BZDs have been reported to be associated with alcohol consumption ${ }^{24}$. This combination is important because of the possibility of mood disorders, excessive sedation, increased risk of falls, memory problems and traffic accidents, especially in the elderly. In contrast, our results showed that older people who used BZD consumed less alcohol. These elderly people potentially should have been instructed not to consume alcohol during treatment.

This study is subject to some limitations, as follows: 1) the crosssectional design is limited to establishing cause and consequence; 2) while the diagnostic examination is important, overestimation of the diagnosis is recognized in structured interviews based on current diagnostic systems ${ }^{29}$; and 3) the results of the multivariate analysis should be interpreted with caution because of the small absolute number of individuals with diagnoses who were investigated.

In conclusion, BZDs are often used by elderly people over long periods of time. Elderly people who make take multiple drugs, especially antidepressants, are more likely to use BZDs, as are those with a clinical diagnosis of depression, anxiety, depression/ anxiety and bipolar disorders. These questions have a direct impact on an increase in morbidity that results from negative effects of psychotropic drug over-prescription and mistreatment of mood and anxiety disorders. 


\section{Acknowledgments}

We would like to thank: 1) "Fundação de Amparo à Pesquisa do Estado do Rio Grande do Sul (Fapergs)" that supported the study with a research grant; 2) "Comissão de Aperfeiçoamento de Pessoal de Nível Superior” (Capes), Brazil - Science without Borders program; public notice A_1/2013 that supported EL Nogueira with a post-doctoral scholarship. Loureiro $\mathrm{F}$ was supported by Capes with a post-doctoral scholarship from the "Programa Nacional de Pós-Doutorado" (public notice: Portaria Capes $\mathrm{n}^{\circ}$ 86/2013); 3) "Secretaria Municipal de Saúde de Porto Alegre" (SMS/ POA), Brazil, for collaboration and non-financial support; and 4) Pontifícia Universidade Católica do Rio Grande do Sul (PUCRS / www.pucrs.br).

\section{Conflicts of interest and financial disclosure}

None was declared.

\section{References}

1. Dellosso B, Lader M. Do benzodiazepines still deserve a major role in the treatment of psychiatric disorders? A critical reappraisal. Eur Psychiatry. 2013;28(1):7-20.

2. Greenblatt DJ, Harmatz JS, Shader RI. Psychotropic drug prescribing in the United States: extent, costs, and expenditures. J Clin Psychopharmacol. 2011;31(1):1-3.

3. Moylan S, Staples J, Ward SA, Rogerson J, Stein DJ, Berk M. The efficacy and safety of alprazolam versus other benzodiazepines in the treatment of panic disorder. J Clin Psychopharmacol. 2011;31(5):647-52.

4. Carrasco-Garrido P, Jiménez-García R, Astasio-Arbiza P, Ortega-Molina P, de Miguel AG. Psychotropics use in the Spanish elderly: predictors and evolution between years 1993 and 2003. Pharmacoepidemiol Drug Saf. 2007;16(4):449-57.

5. Spanemberg L, Nogueira EL, da Silva CT, Dargél AA, Menezes FS, Cataldo Neto A. High prevalence and prescription of benzodiazepines for elderly: data from psychiatric consultation to patients from an emergency room of a general hospital. Gen Hosp Psychiatry. 2011;33(1):45-50.

6. Préville M, Vasiliadis HM, Bossé C, Dionne PA, Voyer P, Brassard J. Pattern of psychotropic drug use among older adults having a depression or an anxiety disorder: results from the longitudinal ESA study. Can J Psychiatry. 2011;56(6):348-57.

7. Rikala M, Korhonen MJ, Sulkava R, Hartikainen S. Psychotropic drug use in community-dwelling elderly people-characteristics of persistent and incident users. Eur J Clin Pharmacol. 2011;67(7):731-9.

8. Brunoni AR, Nunes MA, Figueiredo R, Barreto SM, da Fonseca Mde J, Lotufo PA, et al. Patterns of benzodiazepine and antidepressant use among middle-aged adults. The Brazilian longitudinal study of adult health (ELSA-Brasil). J Affect Disord. 2013;151(1):71-7.

9. Lader M. Benzodiazepine harm: how can it be reduced? Br J Clin Pharmacol. 2014;77(2):295-301.

10. Richardson K, Bennett K, Kenny RA. Polypharmacy including falls riskincreasing medications and subsequent falls in community-dwelling middle-aged and older adults. Age Ageing. 2015;44:90-6.

11. Barcelos-Ferreira R, Izbicki R, Steffens DC, Bottino CM. Depressive morbidity and gender in community-dwelling Brazilian elderly: systematic review and meta-analysis. Int Psychogeriatr. 2010;22(5): 712-26.
12. Nogueira EL, Rubin LL, Giacobbo SS, Gomes I, Cataldo Neto A Rastreamento de sintomas depressivos em idosos na Estratégia Saúde da Família, Porto Alegre. Rev Saúde Pública. 2014;48(3):368-77.

13. Manthey L, van Veen T, Giltay EJ, Stoop JE, Neven AK, Penninx BW, et al. Correlates of (inappropriate) benzodiazepine use: the Netherlands Study of Depression and Anxiety (NESDA). Br J Clin Pharmacol. 2011;71(2):263-72.

14. Lader M. Benzodiazepines revisited - will we ever learn? Addiction. 2011;106(12):2086-109.

15. Lai IC, Wang MT, Wu BJ, Wu HH, Lian PW. The use of benzodiazepine monotherapy for major depression before and after implementation of guidelines for benzodiazepine use. J Clin Pharm Ther. 2011;36(5):577-84.

16. Gomes I, Nogueira EL, Engroff P, Ely LS, Schwanke CHA, De Carli GA, et al. The multidimensional study of the elderly in the family health strategy in Porto Alegre, Brazil (EMI-SUS). Pan Am J Aging Res. 2013;1(1):20-4.

17. Nogueira EL, Moretti PF, Ribeiro Junior FP, Diefenthaeler EC, Cataldo Neto A, Engroff P, et al. The Mental Health Research Protocol of the Multidimensional Study of the Elderly in the Family Health Strategy in Porto Alegre, Brazil (EMI- SUS). Pan Am J Aging Res. 2014;2(1):29-34.

18. Amorim P. Mini International Neuropsychiatric Interview (MINI): validação de entrevista breve para diagnóstico de transtornos mentais. Rev Bras Psiquiatr. 2000;22(3):106-15.

19. de Azevedo Marques JM, Zuardi AW. Validity and applicability of the Mini International Neuropsychiatric Interview administered by family medicine residents in primary health care in Brazil. Gen Hosp Psychiatry. 2008;30(4):303-10.

20. World Health Organization Collaborating Centre for Drug Statistics Methodology. Guidelines for ATC classification and DDD assignment, 2015. Oslo: World Health Organization; 2014.

21. Alvarenga JM, Loyola Filho AI, Firmo JOA, Lima-Costa MF, Uchoa E. Prevalence and sociodemographic characteristics associated with benzodiazepines use among community dwelling older adults: the Bambuí Health and Aging Study (BHAS). Rev Bras Psiquiatr. 2008;30(1):7-11.

22. Windle A, Elliot E, Duszynski K, Moore V. Benzodiazepine prescribing in elderly Australian general practice patients. Aust N Z J Public Health. 2007;31(4):379-81.

23. American Geriatrics Society 2012 Beers Criteria Update Expert Panel. American Geriatrics Society updated Beers Criteria for potentially inappropriate medication use in older adults. J Am Geriatr Soc. 2012;60:616-31.

24. Sonnenberg CM, Bierman EJ, Deeg DJ, Comijs HC, van Tilburg W, Beekman AT. Ten-year trends in benzodiazepine use in the Dutch population. Soc Psychiatry Psychiatr Epidemiol. 2012;47(2):293-301.

25. Gray SL, Eggen AE, Blough D, Buchner D, LaCroix AZ. Benzodiazepine use in older adults enrolled in a health maintenance organization. Am J Geriatr Psychiatry. 2003;11(5):568-76.

26. Barbui C, Cipriani A, Patel V, Ayuso-Mateos JL, van Ommeren M Efficacy of antidepressants and benzodiazepines in minor depression: systematic review and meta-analysis. Br J Psychiatry. 2011;198(1):11-6.

27. Pfeiffer PN, Ganoczy D, Zivin K, Valenstein M. Benzodiazepines and adequacy of initial antidepressant treatment for depression. J Clin Psychopharmacol. 2011;31(3):360-4.

28. Weisberg RB, Dyck I, Culpepper L, Keller MB. Psychiatric treatment in primary care patients with anxiety disorders: a comparison of care received from primary care providers and psychiatrists. Am J Psychiatry. 2007;164(2):276-82.

29. Maj M. "Psychiatric comorbidity": an artefact of current diagnostic systems? Br J Psychiatry. 2005;186:182-4. 